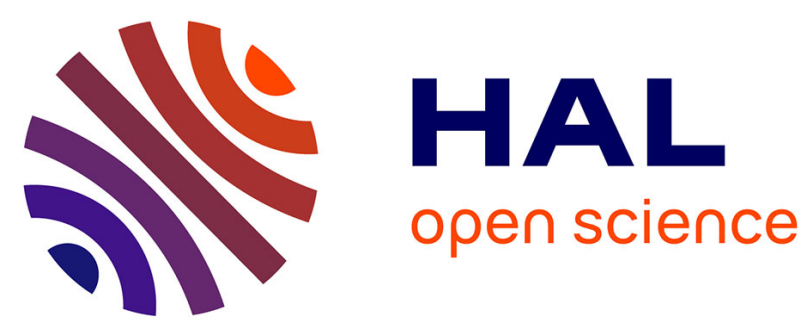

\title{
Fast sorption measurements of volatile organic compounds on building materials: Part 1 - Methodology developed for field applications
}

\author{
Malak Rizk, Marie Verriele, Sébastien Dusanter, Coralie Schoemaecker, \\ Stéphane Le Calvé, Nadine Locoge
}

\section{To cite this version:}

Malak Rizk, Marie Verriele, Sébastien Dusanter, Coralie Schoemaecker, Stéphane Le Calvé, et al.. Fast sorption measurements of volatile organic compounds on building materials: Part 1 Methodology developed for field applications. Building and Environment, 2016, 99, pp.200-209. 10.1016/j.buildenv.2015.12.017 . hal-02303729

\section{HAL Id: hal-02303729 \\ https://hal.science/hal-02303729}

Submitted on 2 Oct 2019

HAL is a multi-disciplinary open access archive for the deposit and dissemination of scientific research documents, whether they are published or not. The documents may come from teaching and research institutions in France or abroad, or from public or private research centers.
L'archive ouverte pluridisciplinaire HAL, est destinée au dépôt et à la diffusion de documents scientifiques de niveau recherche, publiés ou non, émanant des établissements d'enseignement et de recherche français ou étrangers, des laboratoires publics ou privés. 


\section{Accepted Manuscript}

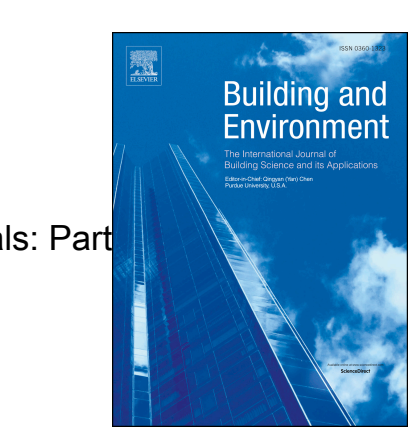

Fast sorption measurements of volatile organic compounds on building materials: Part 1 - Methodology developed for field applications

M. Rizk, M. Verriele, S. Dusanter, C. Schoemaecker, S. Le calve, N. Locoge

PII:

S0360-1323(15)30215-8

DOI:

10.1016/j.buildenv.2015.12.017

Reference: BAE 4348

To appear in: Building and Environment

Received Date: 22 September 2015

Revised Date: 14 December 2015

Accepted Date: 20 December 2015

Please cite this article as: Rizk M, Verriele M, Dusanter S, Schoemaecker C, Le calve S, Locoge N, Fast sorption measurements of volatile organic compounds on building materials: Part 1 - Methodology developed for field applications, Building and Environment (2016), doi: 10.1016/j.buildenv.2015.12.017.

This is a PDF file of an unedited manuscript that has been accepted for publication. As a service to our customers we are providing this early version of the manuscript. The manuscript will undergo copyediting, typesetting, and review of the resulting proof before it is published in its final form. Please note that during the production process errors may be discovered which could affect the content, and all legal disclaimers that apply to the journal pertain. 


\section{$\underline{\text { Graphical abstract }}$}
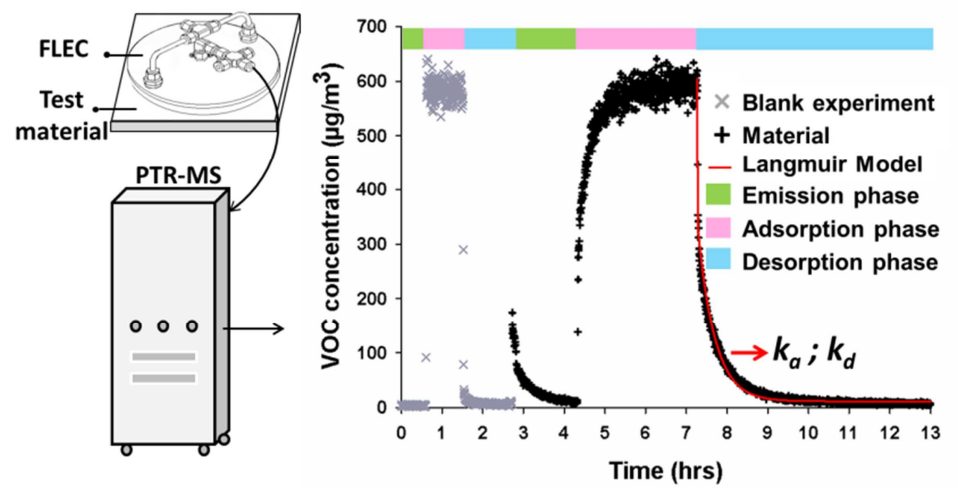
1 Fast sorption measurements of volatile organic

2 compounds on building materials: Part 1 - Methodology

3 developed for field applications

4

5

6

7

8

9

10

11

12

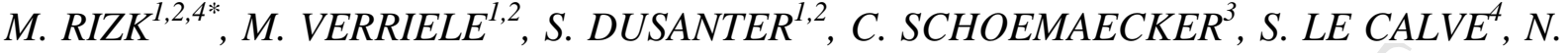 \\ LOCOGE $E^{1,2}$ \\ ${ }^{1}$ Mines Douai, SAGE, F-59508 Douai, France \\ ${ }^{2}$ Université de Lille, F-59000, Lille, France \\ ${ }^{3}$ Université de Lille 1, Laboratoire de Physico-chimie des Processus de Combustion et de \\ l'Atmosphère, Villeneuve d'Ascq, France \\ ${ }^{4}$ Université de Strasbourg/CNRS. Institut de Chimie et Procédés pour l'Energie, \\ l'Environnement et la Santé (ICPEES), UMR 7515, F-67087, Strasbourg.
}

*Corresponding author present address: Mines Douai, 941 Rue Charles Bourseul, CS 10838, 59508 Douai Cedex France ; Phone : +3327 712633 ; e-mail : malak.rizk@mines-douai.fr

\title{
$\underline{\text { Abstract }}$
}

Several physicochemical processes occurring within buildings are key drivers of indoor concentrations of Volatile Organic compounds VOCs. Many models and experimental studies have been proposed to predict VOCs concentration indoors given these processes. However, there is a lack of representative data in literature to present gas-surface interaction in order to validate mathematical models. This work is divided in two parts and aims to develop and validate a method to perform fast measurements of VOC sorption parameters on the field by coupling a Field and Laboratory Emission Cell (FLEC) to a Proton Transfer Reaction-Mass Spectrometer (PTR-MS). In the part 1 of the work, sorption coefficients of aromatic compounds on a gypsum board and vinyl flooring were investigated at ppb levels to test and evaluate the proposed methodology. Sorption coefficients in the range of $0.03-1.88 \mathrm{~m} \cdot \mathrm{h}^{-1}$ for $\mathrm{k}_{\mathrm{a}}$ and 2.04-17.32 $\mathrm{h}^{-1}$ for $\mathrm{k}_{\mathrm{d}}$ were successfully measured within a (0.5-8 hours) for the two materials. Robustness tests highlight that the determination of sorption coefficients does not depend on operating conditions. While sorption coefficients for the gypsum board were measured with a PTR-MS time resolution of 20 seconds, the vinyl flooring material required measurements at a higher time resolution of 2 seconds due to its lower sorption properties. Limits of applicability assessed for this method indicate that sets of sorption parameters $\left(\mathrm{k}_{\mathrm{a}}\right.$, $\left.\mathrm{k}_{\mathrm{d}}\right)$ of $\left(0.01 \mathrm{~m} \cdot \mathrm{h}^{-1} ; 0.01 \mathrm{~h}^{-1}\right)$ and $\left(0.09 \mathrm{~m} \cdot \mathrm{h}^{-1} ; 0.09 \mathrm{~h}^{-1}\right)$ can be measured with an accuracy better than $10 \%$ at time resolutions of 2 and 20 seconds respectively.

\section{$\underline{\text { Keywords }}$}

Field and laboratory emission cell (FLEC), Proton transfer reaction-mass spectrometer (PTRMS), Sorption, VOCs, Building materials. 


\section{Introduction}

Volatile organic compounds VOCs are the main pollutants in indoor environment, which present a strong impact on human health, comfort and productivity [1-3]. Several physicochemical processes occurring within buildings are key drivers of indoor concentrations of VOCs [4]. These processes include heterogeneous and gas-phase chemical reactions, air exchange with outdoor and gas-surface interactions. A good understanding of these processes is important to develop efficient strategies to reduce human exposure to indoor air pollution. The available methods developed in literature to study the concentrations of VOCs indoors, given the above-mentioned processes fall into two categories, modeling approaches and experimental investigation under well-controlled environments.

Under the first category, several models have been developed to simulate the VOC emission/sorption by indoor surfaces. As far as the sorption process is concerned, some models considered the adsorption $\left(\mathrm{k}_{\mathrm{a}}\right)$ and desorption $\left(\mathrm{k}_{\mathrm{d}}\right)$ rates [5-7] while, other accounted for the diffusion coefficient $\left(\mathrm{D}_{\mathrm{m}}\right)$ in the building material and represents the sorption with a partitioning coefficient $(\mathrm{K})$ between the air and the material through a diffusion-controlled mass transfer model proposed by Little [8]. Later Deng [9] proposed an improved model that considers for the convective mass transfer coefficient $\left(\mathrm{h}_{\mathrm{m}}\right)$ through the boundary layer present on the surface of a material as well as the diffusion and the partitioning coefficients. For the emission process, the diffusion-controlled mass transfer model proposed by Little [8] promoted the development of the emissions mass transfer model such as the model of Xu [10] applied for single-layer building material, the model of Lee [11] applied for porous materials and the model of $[12,13]$ applied for multilayer building materials. A general model was developed by Xiong [14] to characterize both emission and sorption process in ventilated and airtight chambers taking into account the convective mass transfer coefficient, the diffusion coefficient $\left(\mathrm{D}_{\mathrm{m}}\right)$ and the partitioning coefficient $(\mathrm{K})$. All these models are presented in the reviews of Liu [13] and a comparison between some of the typical models is given elsewhere [15] . Nevertheless, all the mentioned-above models consider only the gas-surface interactions and neglect the chemical reactions that can take place indoors in both homogenous and heterogeneous phases. Therefore, some studies $[16,17]$ proposed indoor air quality models which accounts for the effect of ventilation, deposition of inorganic species on surfaces, emission and photochemistry reactions with a consideration for a perfect mixing of the air inside simulated room. However, these photochemistry models neglects the sink behavior of surfaces.

Concerning the experimental investigations, only laboratory studies have provided adsorption $\left(\mathrm{k}_{\mathrm{a}}\right)$ and desorption $\left(\mathrm{k}_{\mathrm{d}}\right)$ rate coefficients for VOCs on surfaces, to describe the role of these interactions on VOCs indoors concentrations. The experimental procedure is based on the exposure of sample materials, inside an emission test chamber, to artificially polluted atmospheres containing several ppm of VOCs [7, 18-20]. The mixing ratios of VOCs used in these experiments are several orders of magnitude higher than those observed in indoor environments at ppb levels [21] and are then not representative. These works were conducted considering either a single organic compound and a single material [7, 18, 22, 23] or mixtures of VOCs and combinations of materials [5, 24, 25]. To extract the parameters of interest, 
experimental concentration profiles, usually measured by gas chromatography techniques, are fitted by a relevant model, more or less complex as already presented above, depending on the processes considered (sorption processes, diffusion into the material, and diffusion through the boundary layer formed above the material surface) and the type of material (homogenous or porous media). .

However, when sorption coefficients derived from chamber experiments was incorporated in indoor air quality (IAQ) models, a significant differences as high as a factor of 9 [6] was shown between modeled concentrations and ambient observations made in test houses. This disagreement may be due to sorption coefficients for real indoor surfaces that are different than those measured during laboratory experiments [6] because the implementation of a material in a real environment and its aging due to varying environmental conditions can affect its sorption properties compared to those observed in laboratory chambers. In addition, the use of inappropriate models to describe real situations can leads to this disagreement as already highlighted by $\mathrm{Xu}[10]$.

Given the studies mentioned above, there is actually a need to:

- Develop a model that account for all physical and chemical processes occurring indoors such as emission, outdoor input, chemical reactivity and also sorption on the surface of building materials and,

- Validate proposed models using more representative experimental data from real environment to determine the influence of each process on the VOCs concentration indoors.

Consequently, a research project called MERMAID (Mesures Expérimentales Représentatives et Modélisation Air Intérieur Détaillée / Representative Experimental Measurement-Indoor Air Detailed Model) was designed to address the leaks found in literature as already mentioned above [26]. The originality of the MERMAID project is the combination between an experimental approach based on several types of measurements for VOCs, inorganic gases, particulate matter and reactive species to a modeling approach based on a detailed indoor air quality model called INCA-Indoor, including the physical and chemical processes. Concerning the sorption processes, the INCA-indoor model proposed by Mendez [27] treats the sorption of VOCs on the surface of building materials through the adsorption $\left(\mathrm{k}_{\mathrm{a}}\right)$ and desorption $\left(\mathrm{k}_{\mathrm{d}}\right)$ coefficients represented as a function of the mass transfer coefficient $\left(\mathrm{h}_{\mathrm{m}}\right)$ in the boundary layer. However, the INCA-Indoor model neglects the diffusion or the mass transfer in the inner of the material since several inputs parameters are needed which is difficult to determine on the field (effective diffusion coefficients, initial concentration in the materials...etc) and which also requires computational efforts to solve diffusion equations. Nevertheless, the emission rate coefficient is taken into account to represent the mass transfer in the inner of the material. To meet the objective of the MERMAID project, this study aims to develop a methodology suitable to perform in-situ fast measurements of VOC sorption coefficients in indoor environments and under real conditions. Derived experimental parameters will be useful as data inputs to INCA-indoor air quality model. 
This work aims to develop a method to determine in a fast and simple way the sorption parameters on the surface of a material present in indoor environment. Therefore this work is divided in three steps:

(1) Develop a new device based on a field and laboratory emission cell (FLEC) coupled to a proton transfer reaction mass spectrometer (PTRMS);

(2) Validate the proposed methodology during laboratory experiments to assess the feasibility of fast in-situ measurements and the limitations of the method applicability; and

(3) Compare this method to the traditional emission test chamber method used usually in literature to perform sorption measurements.

Only the findings of the first two steps are presented in this part of the study and the comparison with the traditional method is presented in the part 2 which includes a discussion on the usage of the experimental data in the INCA-Indoor model. Therefore, in this first part of the work the sorption properties of a mixture of aromatic VOCs at ppb levels were investigated on an unpainted gypsum board and vinyl flooring presenting contrasting sorption behavior [18]. These VOCs are considered as ubiquitous compounds in indoor environments and presents a large fraction of total VOC concentrations [21, 28-30]. Moreover, BTEX were chosen to test the proposed methodology, because they can be easily purchased in certified cylinders and are not prone to memory effects on sampling materials.

\section{Materials and Methods}

\subsection{Chemicals}

For all the experiments, the BTEX mixture was provided by Air products and contained the following VOC in the mixing ratio of 2 for benzene, 6 for toluene, 1 for ethyl benzene, 2 for p-xylene and 1 for o-xylene.

\subsection{Test materials}

An unpainted 12.5-mm thick gypsum board and a 2.4-mm thick piece of vinyl flooring were used. Several samples of each material were stored at $4^{\circ} \mathrm{C}$ for three months before the experiments to ensure that replicate measurements are performed on samples having the same aging history.

\subsection{Experimental setup}

The setup used in this study is based on coupling a FLEC (Chematec) and a high resolution PTR-MS (PTR-ToFMS, Kore technology) and presented in Figure 1. The FLEC inlet is connected to two gas generation systems using a three-way valve. The first generation system is composed of a dry zero air generator (Claind) and a humidificator made of a water bubbler and mass flow controllers $(M K S)$. This system is used to supply the FLEC with humid clean air at constant flow rate $\left(200-500 \mathrm{ml} \cdot \mathrm{min}^{-1}\right)$ and stable relative humidity $\left(50 \pm 5 \%\right.$ at $\left.23 \pm 2^{\circ} \mathrm{C}\right)$. The second generation system is made of a VOC cylinder connected to a dilution system ( $\mathrm{Gas}$ Calibration Units - Ionicon Analytik), which is used to dilute the VOC mixture at a constant 
relative humidity of 50\%. The FLEC's outlet is connected to the PTR-MS to quantify VOC concentrations exiting the cell. An exhaust is left at atmospheric pressure to prevent a pressure build-up in the FLEC apparatus.

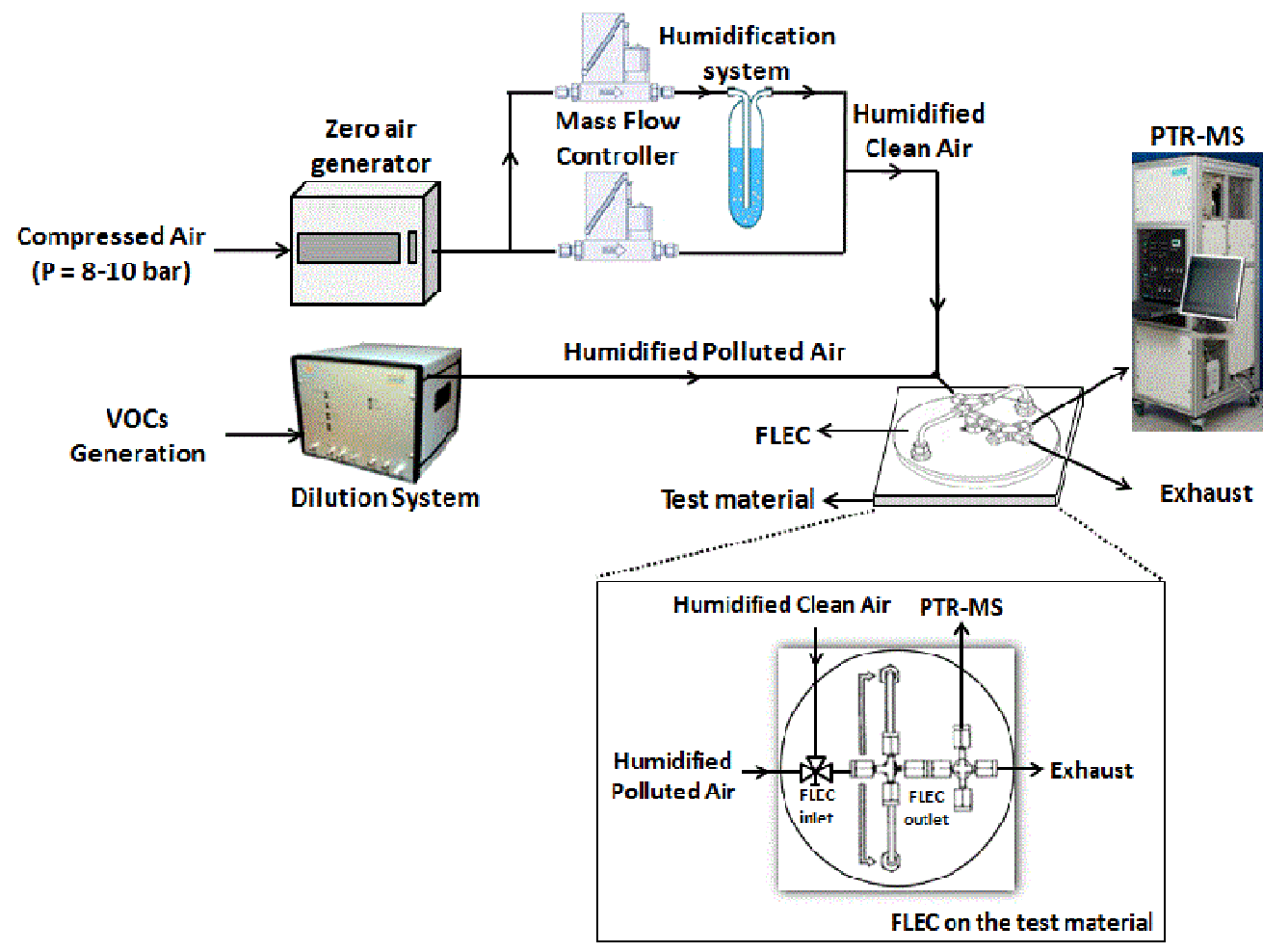

Figure 1. Experimental setup for measuring adsorption and desorption coefficients of VOCs on building materials.

The FLEC can be easily handled and fixed on surfaces and the PTR-MS instrument was designed for easy and safe transportation. In fact, the deployment of PTRMS instruments has been demonstrated during field campaigns in ambient air [31] and for indoor studies [32]. This setup exhibits reasonable dimensions to be used during intensive field campaigns for research purposes in buildings but is not proposed as a tool for quick indoor air diagnostics due to its high price and high weight.

FLEC. The FLEC ${ }^{\circledR}$ is a portable tool commercialized by CHEMATEC, which can be exposed on flat and non-porous surfaces to investigate gas-surface interactions. Technical details have been provided elsewhere [33]. When the cell is exposed on a flat material, it covers a surface area of $177 \mathrm{~cm}^{2}$, leading to a loading factor of $506 \mathrm{~m}^{2} \cdot \mathrm{m}^{-3}$. It has a small internal volume $(35 \mathrm{~mL})$, which allows conducting fast sorption experiments (a few hours) compared to laboratory emission test chambers of several liters (a few days).

PTR-MS. The PTR-MS was chosen as a fast analytical tool to accurately monitor the fast variations of VOC concentrations at the sub ppb level [34] with time resolutions in the range of 2-20 seconds. As shown in the result section, the measurement time resolution is a critical parameter to correctly describe fast sorption processes taking place at the material surface inside the FLEC apparatus. The PTR-MS technique has been described in detail elsewhere [34]. As proposed by De Gouw [34], signals of protonated VOCs are normalized to $\mathrm{H}_{3} \mathrm{O}^{+}$and $\mathrm{H}_{3} \mathrm{O}^{+}\left(\mathrm{H}_{2} \mathrm{O}\right)$ to correct for a small humidity dependence of the PTR-MS response. 
$\mathrm{H}_{3} \mathrm{O}^{+}\left(\mathrm{H}_{2} \mathrm{O}\right)$ is an ionic cluster that is formed when humid samples are analyzed. Detected VOC signals are then converted to concentrations $\left(\mu \mathrm{g} \cdot \mathrm{m}^{-3}\right)$ using calibration coefficients determined experimentally for each targeted species. In the following, ethylbenzene and o/pxylene are referred as $\mathrm{C} 8$-aromatics due to their detection as a sum of isobaric compounds with the PTR-MS. Calibration coefficients were measured before each experiment using zero air and a standard mixture of VOCs provided by IONICON. Response factors measured over a period of 3 months indicate a good stability of the PTR-MS instrument with a relative standard deviation for each species in the range 9-10\%. In addition, the stability of the PTRMS response over the time of a sorption experiment (only a few hours) is estimated to be better than $3 \%$ from differences observed between subsequent calibrations performed every 23 days. VOCs background signals measured using zero air were used to estimate detection limits (LOD) as three times the standard deviation on the zero measurements. Measured LODs are less than $3.4,4.7$ and $11 \mu \mathrm{g} \mathrm{m}^{-3}$ for a time resolution of 20,10 and 2 seconds respectively and which is low enough to measure accurately the concentrations used in this study (See Table 1- [15]).

\subsection{Experimental protocols}

First of all, a blank experiment is carried out on a Pyrex glass before each sorption experiment on a tested material and using the same procedure. This experiment, referred as "No sink" in the following, allows evaluating sorption processes on internal surfaces of the FLEC apparatus and the Teflon tubing. A sorption experiment involves a 3-step procedure as described in the following. The FLEC is first exposed on a material and supplied with humidified zero air. When concentrations reach relatively steady state, the FLEC is supplied with humid air containing targeted VOCs. This second phase is named "adsorption phase" as illustrated in Figure 2. During this step, VOCs concentrations increase until an equilibrium is reached where the concentrations are equal to those registered for the adsorption phase already performed on the Pyrex glass. Once the VOCs concentrations are stable (Figure 2: $t_{\text {eq }}$ ), humidified zero air is provided to the cell instead of the VOCs mixture. This third phase is named "desorption phase". During this step, VOC concentrations decrease until steady concentrations similar to those reached in the end of the first phase, are observed (Figure 2). Standard operating conditions were defined as an air temperature of $23 \pm 2{ }^{\circ} \mathrm{C}$ and a relative humidity of $50 \pm 5 \%$ for all experiments described in this study.

The feasibility of measuring sorption parameters with the FLEC/PTR-MS coupling was first investigated by repeating the same experiment on a gypsum board and a piece of vinyl

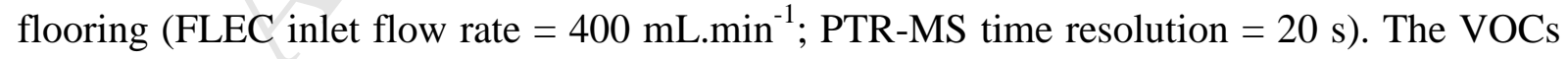
concentrations used for the adsorption phase were closed to $565 \mu \mathrm{g} . \mathrm{m}^{-3}$ for toluene, $434 \mu \mathrm{g} . \mathrm{m}^{-}$ ${ }^{3}$ for $\mathrm{C} 8$ aromatics, and $160 \mu \mathrm{g} \cdot \mathrm{m}^{-3}$ for benzene. The VOC steady-state-concentrations measured before the sorption experiment by exposing the material to humidify zero air, are negligible and represent less than $3 \%$ of $\mathrm{C}_{\mathrm{e}}$. A second set of experiments was carried out on the gypsum board to test the robustness of this method. It consisted in assessing (1) the repeatability on 5 different samples (of the same board); (2) the repeatability of 4 tests performed consecutively on the same sample; (3) the influence of VOCs concentrations 
(threefold variation); and (4) the influence of different inlet flow rates (threefold variation) keeping VOCs concentrations unchanged. Experimental conditions are listed in Table 1.

Table 1. Experimental conditions used to perform tests of robustness on an unpainted gypsum board at a PTR-MS time resolution of 20 sec.

\begin{tabular}{|c|c|c|c|c|c|c|c|c|c|c|c|c|}
\hline \multirow[b]{2}{*}{ Test } & \multirow{2}{*}{\multicolumn{3}{|c|}{$\begin{array}{l}\text { Flow rate } \\
\left(\mathbf{m L} \cdot \mathbf{m i n}^{-1}\right)\end{array}$}} & \multirow{2}{*}{\multicolumn{3}{|c|}{$\begin{array}{c}\text { Air exchange } \\
\text { rate } \\
\left(h^{-1}\right)\end{array}$}} & \multirow{2}{*}{\multicolumn{3}{|c|}{$\begin{array}{c}\text { Specific flow } \\
\text { rate per unit of } \\
\text { surface } \\
{\left[\mathbf{m}^{3} /\left(\mathbf{h}^{2} \mathbf{m}^{2}\right)\right]} \\
\end{array}$}} & \multicolumn{3}{|c|}{ Concentration $\left(\mu \mathrm{g} . \mathrm{m}^{-3}\right)$} \\
\hline & & & & & & & & & & Benzene & $\begin{array}{c}\text { C8 } \\
\text { aromatics }\end{array}$ & Toluene \\
\hline $\begin{array}{c}\mathbf{R} \\
(\mathrm{n}=5)\end{array}$ & \multicolumn{3}{|c|}{300} & \multicolumn{3}{|c|}{514} & \multicolumn{3}{|c|}{1.0} & 106 & 289 & 377 \\
\hline $\begin{array}{c}M \\
(n=4)\end{array}$ & \multicolumn{3}{|c|}{300} & \multicolumn{3}{|c|}{514} & \multicolumn{3}{|c|}{1.4} & 106 & 289 & 377 \\
\hline $\begin{array}{c}\mathbf{F} \\
(\mathbf{n}=3)\end{array}$ & 300 & 400 & 500 & 514 & 686 & 857 & 1.0 & 1.4 & 1.7 & 106 & 289 & 377 \\
\hline \multirow{3}{*}{$\underset{(n=3)}{C}$} & \multirow{3}{*}{\multicolumn{3}{|c|}{400}} & \multirow{3}{*}{\multicolumn{3}{|c|}{686}} & \multirow{3}{*}{\multicolumn{3}{|c|}{1.4}} & 479 & 868 & 1131 \\
\hline & & & & & & & & & & 319 & 434 & 565 \\
\hline & & & & & & & & & & 106 & 289 & 377 \\
\hline
\end{tabular}

n: number of experiments; $R=$ Repeatability tests performed on different samples of the same board; M= Multiple successive measurements (replicates on the same sample); F= Inlet flow rate tests performed using three different air flow and $C=$ Concentrations tests performed using three different concentrations.

\section{Theory and data treatment}

The data analysis yields values for $\mathrm{C}_{\mathrm{se}}$ the mass of VOCs in the sink per unit area of the material at equilibrium $\left(\mu \mathrm{g} \cdot \mathrm{m}^{-2}\right), \mathrm{k}_{\mathrm{a}}$ the adsorption rate constant $\left(\mathrm{m} \cdot \mathrm{h}^{-1}\right), \mathrm{k}_{\mathrm{d}}$ the desorption rate constant $\left(\mathrm{h}^{-1}\right)$ and $\mathrm{K}_{\mathrm{e}}\left(\mathrm{k}_{\mathrm{a}} / \mathrm{k}_{\mathrm{d}}\right)$ the equilibrium constant $(\mathrm{m})$ described in the following.

\subsection{Determination of $C_{s}$}

Based on the experimental procedure described above, the mass of VOCs adsorbed on the material is in steady state at time $t_{\text {eq. }}$. The total mass adsorbed or desorbed by a material corresponds to the area between the sorption curves (FLEC exposed on a material) and the "no sink" curve (FLEC exposed on pyrex), for the adsorption and the desorption phases respectively (Figure 2).

Equations (1) and (2) were used to calculate the absorbed and the desorbed mass of VOC respectively.

$$
\begin{gathered}
C_{s e}=\int_{t_{0}}^{t_{e q}} \frac{C_{g} \times F}{A} d t \\
C_{s e}=\int_{t_{e q}}^{t_{f}} \frac{C_{g} \times F}{A} d t
\end{gathered}
$$

where, $F$ is the flow rate at the FLEC's inlet $\left(\mathrm{m}^{3} \cdot \mathrm{h}^{-1}\right), A$ the surface area of the material covered by the cell $\left(177 \times 10^{-4} \mathrm{~m}^{2}\right)$, and $t$ the exposure time to the VOCs mixture $(\mathrm{h})$.

\subsection{Determination of $k_{a}$ and $k_{d}$}


The model used to derive sorption parameters from experimental data is the Tichenor model based on the Langmuir theory [7]. This model is based on the assumption that the concentration of a species in bulk air is homogeneous and proportional to the surface concentration. However, this model neglects the diffusion $\left(\mathrm{D}_{\mathrm{m}}\right)$ inside the material and the mass transfer coefficient $\left(\mathrm{h}_{\mathrm{m}}\right)$ between the surface of the material and the bulk air. Despite these limits, this model is suitable for this work to determine $k_{a}$ and $k_{d}$ coefficients, for the reasons detailed below. Zhang [35] studied the flow filed in the FLEC cavity and calculated the local Sherwood number $\mathrm{Sh}_{\mathrm{L}}$ for the different flow rates (186 to $509 \mathrm{~mL} \cdot \mathrm{min}^{-1}$ ). According to this work, the mass transfer coefficient was calculated in the FLEC cavity for the different flow rates used in Table 1 (See Figure 1 in [36]). The flow field in the FLEC is laminar because the Reynolds number $R_{\mathrm{e}}$ varies between 1.4 and 2.3 for. $316 \mathrm{~mL} / \mathrm{min}$ and $509 \mathrm{~mL} / \mathrm{min}$ respectively $\left(\mathrm{R}_{\mathrm{e}}<2000\right.$ for laminar flow). The mass transfer coefficient is very high on the FLEC periphery and decreases in the center to reach a value varying between 1.4 and 2.3 $\mathrm{m} . \mathrm{h}^{-1}$. The mass transfer coefficient $\mathrm{h}_{\mathrm{m}}$, is always higher than the specific flow rate per unit of surface (Table 1) which means that the that any substance present on the surface of the material is immediately diffused in the transverse direction of the flow by molecular diffusion as already highlighted by Zhu [37]. Therefore, the effect of the mass transfer coefficient is not significant on the concentrations in the FLEC cavity and the concentration measured in the FLEC is considered uniform in the entire cavity $\left(\mathrm{C}_{\mathrm{g}}\right)$ as Zhang [35] confirmed previously by conducting experimental and numerical studies of the fluid flow and the convective mass transfer coefficients in a FLEC. They concluded that the air becomes nearly saturated shortly after it begins to flow on the emission surface, due to the small spacing between the cap and the bottom surface. Concerning the diffusion in the inner of the material, this parameter is neglected in this work and supposed to be slower than the instantaneous adsorption on the surface of the material, since the FLEC-PTRMS method is dedicated to fast in-situ measurements and the INCA-indoor model neglects the diffusion in the inner of the material. It worth to note that further works will use a model that considers the diffusion coefficient in the inner of the material to determine the diffusion coefficient and this point will be discussed later in this paper.

Giving the reasons above, the concentration variations $\left(\mathrm{dC}_{\mathrm{g}} / \mathrm{dt}\right.$ and $\left.\mathrm{dC}_{\mathrm{s}} / \mathrm{dt}\right)$ observed in a chamber depends on the adsorption $\left(\mathrm{k}_{\mathrm{a}}\right)$ and desorption $\left(\mathrm{k}_{\mathrm{d}}\right)$ coefficients, as shown in the following equations:

$$
\begin{aligned}
& \frac{d C_{g}}{d t}=N C_{i n}-N C_{g}-k_{a} C_{g} L+k_{d} C_{s} L \\
& \frac{d C_{s}}{d t}=k_{a} C_{g}-k_{d} C_{s}
\end{aligned}
$$

where, $N$ is the air exchange rate $\left(\mathrm{h}^{-1}\right), C_{i n}$ the VOC concentration at the chamber inlet performed $\left(\mu \mathrm{g} \cdot \mathrm{m}^{-3}\right), C_{g}$ the gas-phase VOC concentration inside the chamber $\left(\mu \mathrm{g} \cdot \mathrm{m}^{-3}\right), k_{a}$ the adsorption rate constant $\left(\mathrm{m}^{-1} \mathrm{~h}^{-1}\right), k_{d}$ the desorption rate constant $\left(\mathrm{h}^{-1}\right), C_{s}$ the surface concentration $\left(\mu \mathrm{g} \cdot \mathrm{m}^{-2}\right)$, and $L$ the loading factor $\left(\mathrm{m}^{2} \cdot \mathrm{m}^{-3}\right)$. 
The model used to fit the experimental observations is characterized by equations (3) and (4). Analytical solutions given in equations (5) and (6) can be derived for the desorption phase using the following initial conditions at $\mathrm{t}_{\mathrm{eq}}: t=0 ; C_{g}(0)=C_{e}$ and $C_{s}(0)=C_{s e}=C_{e}\left(k_{a} / k_{d}\right)$.

$$
\begin{aligned}
C_{g}(t) & =\frac{C_{e}\left[\left(N-r_{2}\right) e^{-r_{1} t}-\left(N-r_{1}\right) e^{-r_{2} t}\right]}{r_{1}-r_{2}} \\
C_{s}(t) & =\frac{C_{e} k_{a}\left[r_{1} e^{-r_{2} t}-r_{2} e^{-r_{1} t}\right]}{k_{d}\left(r_{1}-r_{2}\right)}
\end{aligned}
$$

where, $r_{1,2}=\frac{\left(N+k_{a} L+k_{d}\right) \pm\left[\left(N+k_{a} L+k_{d}\right)^{2}-4 N k_{d}\right]^{1 / 2}}{2}$

To determine $\mathrm{k}_{\mathrm{a}}$ and $\mathrm{k}_{\mathrm{d}}$, the concentration time profiles $\mathrm{C}_{\mathrm{g}}(\mathrm{t})$ measured from $\mathrm{t}_{\mathrm{eq}}$ to the end of the test (desorption phase) is fitted using equation (5) and a non-linear least square regression procedure in SigmaPlot ${ }^{\mathrm{TM}} \cdot \mathrm{C}_{\mathrm{e}}$ is the average concentration observed in the gas-phase at the end of the adsorption phase. $\mathrm{N}, \mathrm{L}$ and $\mathrm{C}_{\mathrm{e}}$ are experimental parameters so that they are constrained during the fit.

\section{4. $\underline{\text { Results }}$}

\subsection{Technical feasibility}

Time-resolved concentration profiles obtained for toluene are shown in Figure 2 for two experiments performed on a gypsum board and a piece of vinyl flooring. Concentration profiles of other compounds are given elsewhere (see Figure 2 in [15]) and exhibit the same behavior.
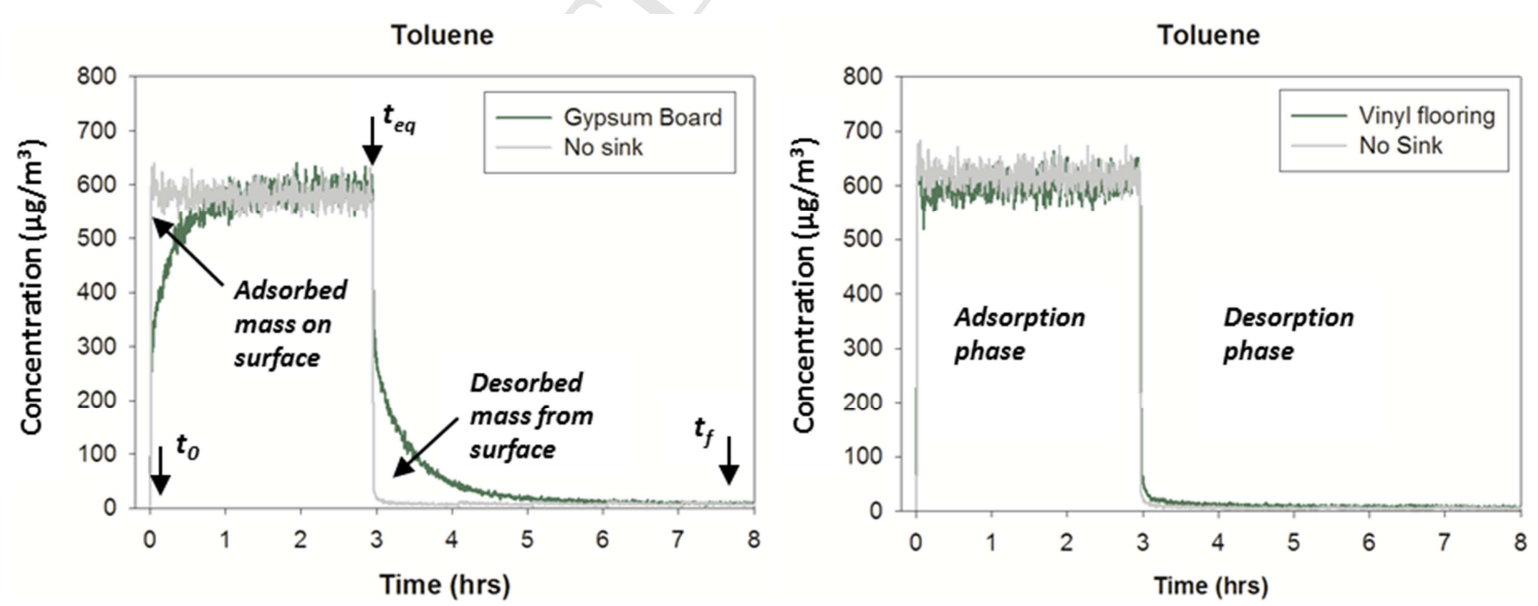

Figure 2. Concentration profiles measured during sorption experiments on a gypsum board and a piece of vinyl flooring for benzene, C8 aromatics and toluene. The "no sink" plot is also shown for comparison.

The concentration profiles indicate that the duration of a sorption experiment is about (0.5-8 hours), which is faster than that observed for regular chamber experiments, usually few days $[7,18]$. The experimental no sink profile obtained using Pyrex glass indicate that VOC sorption on the FLEC internal walls is negligible since no difference can be observed with the 
theoretical no sink profile obtained according to the equation $C_{g}(t)=C_{e} e^{-N t}$. In addition, these results figure out different sorption behaviors for the 2 materials as seen from the total mass adsorbed on the material at equilibrium and the time needed to reach this equilibrium.

Similar concentration profiles are observed for vinyl flooring and pyrex, suggesting low sorption properties for this material. As a consequence, experiments discussed below to characterize the proposed methodology were only performed using the gypsum board, which exhibit significant sorption properties. Values of $k_{a}$ and $k_{d}$ were evaluated for the gypsum board by fitting Equation (4) to concentration profiles acquired during the desorption phase as described in the theory and data treatment section. Obtained values for $\mathrm{k}_{\mathrm{a}}$ and $\mathrm{k}_{\mathrm{d}}$ are respectively $\left(3.2 \mathrm{~m} \cdot \mathrm{h}^{-1}-24 \mathrm{~h}^{-1}\right)$ for benzene, $\left(1.3 \mathrm{~m} \cdot \mathrm{h}^{-1}-1.6 \mathrm{~h}^{-1}\right)$ for $\mathrm{C} 8$ aromatics and $\left(1.7 \mathrm{~m} \cdot \mathrm{h}^{-1}\right.$ $5.5 \mathrm{~h}^{-1}$ ) for toluene. The modeled curves shown in Figure 3 are in good agreement with experimental observations because the correlation coefficient $R^{2}$ is very close to 1 ( 0.96 for benzene, 0.97 for $\mathrm{C} 8$ aromatics and 0.97 for toluene). This good agreement is also observed for the first minutes of the experiments (Figure 3 (d)) contrary to some previous studies made using emission chambers [7, 38].
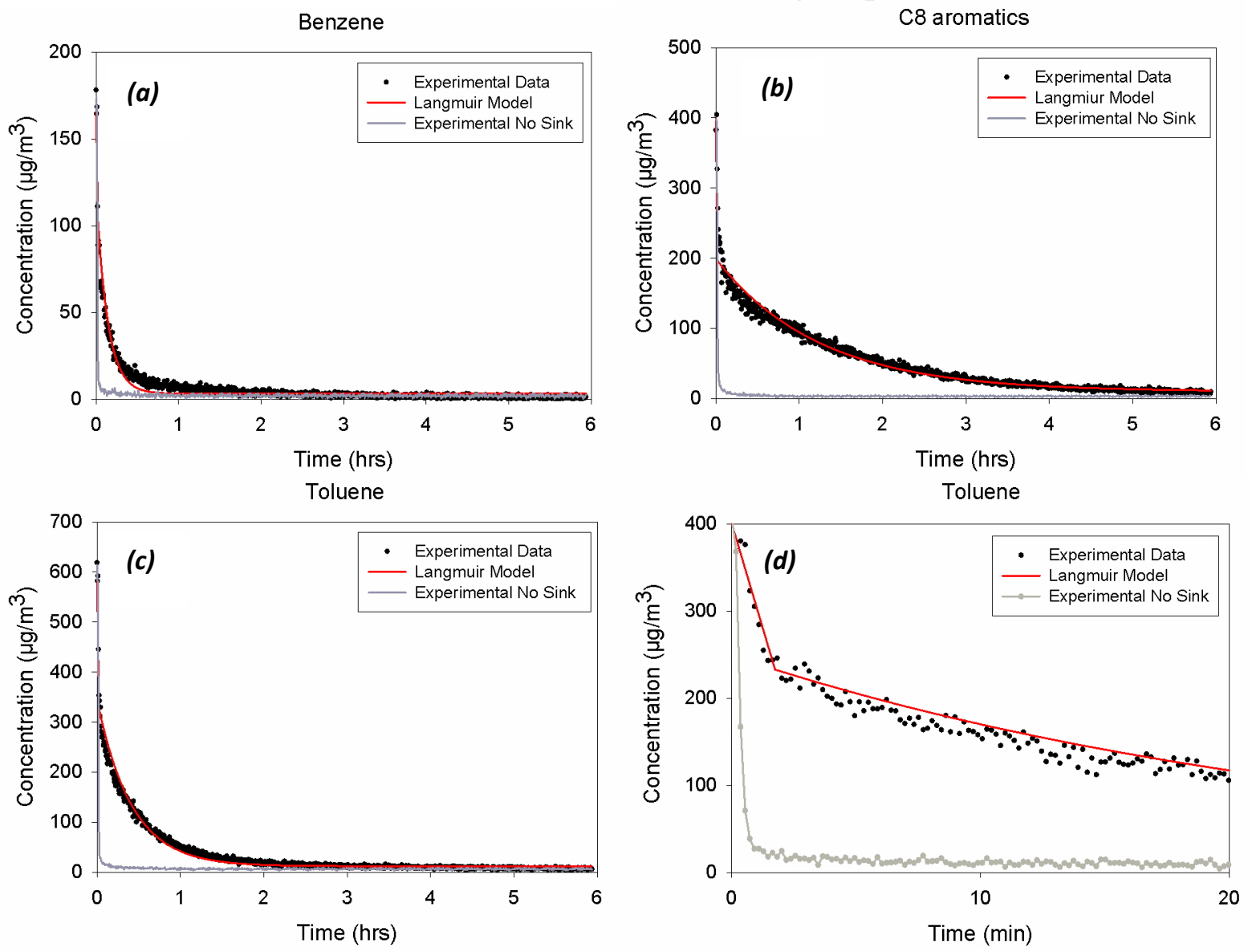

Figure 3. Analysis of the desorption phase for the gypsum board: Benzene (a), C8 aromatics (b), and toluene $(c, d)$. The "no sink" curve is also shown in grey for comparison. The first minutes of the toluene decay are expended in panel (d) to evaluate the "best-fit" curve.

\subsection{Robustness}


Figure 4 shows mean values of $\mathrm{k}_{\mathrm{a}}, \mathrm{k}_{\mathrm{d}}$ and $\mathrm{K}_{\mathrm{e}}$ measured for the targeted VOCs for the Gypsum board and using experimental conditions described above in Table 1. The first set of experiments made on different samples of the same gypsum board ( $\mathrm{R}$ in Figure 4) indicates a good repeatability for the 5 tests, with RSD $(1 \sigma)$ values lower than $17 \%$ for $k_{a}, k_{d}$, and $K_{e}$. Four adsorption/desorption cycles ( $\mathrm{M}$ in Figure 4) made successively on the same sample also show a good repeatability for $\mathrm{K}_{\mathrm{e}}, \mathrm{k}_{\mathrm{a}}$, and $\mathrm{k}_{\mathrm{d}}$, with RSD values lower than $12 \%$, except for benzene for which the RSD reaches $38 \%$ for $k_{d}$. The high uncertainty seen on the determination of benzene sorption parameters is due to the fact that the benzene profile is close to that obtained on pyrex glass, having negligible sorption effect. The uncertainty on the determination of low sorption values will be discussed later in this work. Tests performed at different VOCs concentrations ( $\mathrm{C}$ in Figure 4), as well as different inlet flow rates ( $\mathrm{F}$ in Figure 4), give consistent results for sorption parameters with RSD values lower than $12 \%$ for C8 aromatics and toluene but around $40 \%$ for benzene. These results highlight that the determination of sorption coefficients does not depend on operating conditions such as the VOCs concentration used, the inlet flow rate, and the number of measurements made previously on the investigated material.
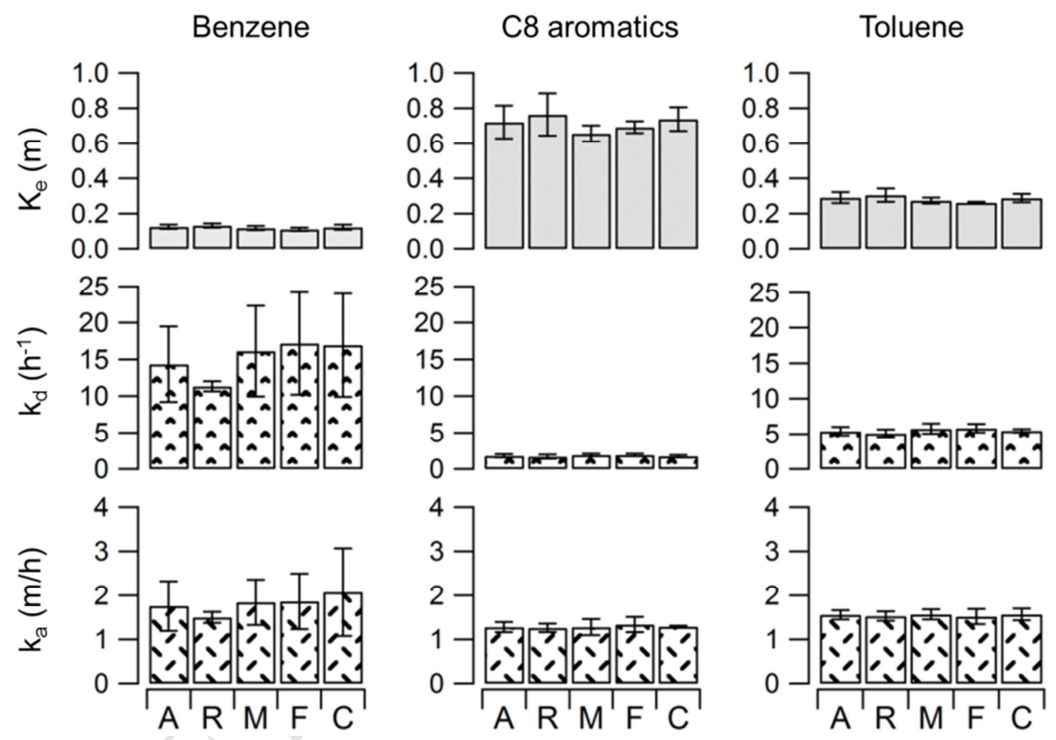

Figure 4. Average results for $k_{a}, k_{d}$ and $K_{e}$ measured on the gypsum board using a mixture of aromatic compounds ( $A=$ All experiments; $R=$ Repeatability experiments; $M=$ Multiples adsorptiondesorption experiments on the same piece of material; $F=$ different air flow rates at the FLEC inlet; $C=$ different concentrations of VOCs). Error bars correspond to 1 standard deviation.

\section{Discussion}

\subsection{Method evaluation}

Based on the results shown above, the FLEC/PTR-MS coupling appears as a promising setup to measure sorption coefficients of VOCs on building materials within a few hours (1-16 hours). Compared to common test chamber experiments usually conducted over 27-600 hours (i.e. over 1-24 days) [18-20, 38, 39], the experimental time is reduced by a factor of 54-75. This method exhibits also a good repeatability and the determination of sorption coefficients is independent on gas concentration or the number of tests investigated on the same sample. 
In addition, derived parameters are independent on flow rates conditions, which validated the choice of the Langmuir model to extract sorption parameters from experiments performed using an enclosure where the gas-phase concentration above the material is homogenous under the conditions of this study.

The applicability of the Langmuir isotherm was verified by investigating the partitioning of VOCs between the gas and adsorbed phases when the equilibrium is reached. The relationship between $\mathrm{C}_{\mathrm{se}}$ (calculated from equations 1 and 2) and $\mathrm{C}_{\mathrm{e}}$ (experimental measurements) for the Gypsum board and target VOCs, shows a linear trend with a correlation coefficient of 0.92 , 0.80 and 0.94 respectively for benzene, C8 aromatics and toluene (See Figure 3 in [15]). According to the relation $\left(\mathrm{C}_{\mathrm{se}}=\mathrm{C}_{\mathrm{e}} \times \mathrm{K}_{\mathrm{e}}\right)$, the slope of the regression line should be equal to $\mathrm{K}_{\mathrm{e}}$. The slope determined for benzene (0.16), C8 aromatics (0.66) and toluene (0.29) is in excellent agreement with the average $\mathrm{K}_{\mathrm{e}}$ value derived from 15 measurements presented in Figure 4. This linear relationship confirms that Langmuir equilibrium can be applied at the concentrations used in this study $\left(106-1131 \mu \mathrm{g} \cdot \mathrm{m}^{-3}\right)$.

In order to test the robustness of the fitting procedure, multiple fits have been performed for several sorption experiments by varying the end-time of desorption phase (Table 2). All desorption phases were performed for 450 minutes and then were analyzed for three different time durations of 450, 300, and 200 minutes.

Table 2. Comparison between $k_{a}$ and $k_{d}$ values derived from the fitting procedure applied to the gypsum board. All experimental measurements were made for duration of 450 minutes. Mathematical fits were performed using an end-time set at 450, 300, and 200 minutes of the desorption phase. Errors correspond to $1 \sigma$ standard deviation. Number of replicates $=5$.

\begin{tabular}{ccccccc}
\hline $\begin{array}{c}\text { Time of } \\
\text { desorption } \\
\text { phase (min) }\end{array}$ & \multicolumn{2}{c}{ Benzene } & \multicolumn{2}{c}{$\mathbf{C 8}$ aromatics } & \multicolumn{2}{c}{ Toluene } \\
\hline 450 & $1.8 \pm 0.57$ & $16 \pm 5.2$ & $1.3 \pm 0.11$ & $2,0 \pm 0.24$ & $1.6 \pm 0.11$ & $6.2 \pm 0.59$ \\
300 & $1.6 \pm 0.16$ & $12 \pm 1.1$ & $1.3 \pm 0.10$ & $1.8 \pm 0.32$ & $1.6 \pm 0.05$ & $5.2 \pm 0.35$ \\
200 & $1.7 \pm 0.24$ & $15 \pm 3.4$ & $1.2 \pm 0.13$ & $2.1 \pm 0.35$ & $1.6 \pm 0.04$ & $5.8 \pm 0.69$ \\
\hline
\end{tabular}

This test indicates that determinations of $k_{a}$ and $k_{d}$ are robust for these 3 experimental durations. Deviations between individual calculated values and mean values (of all sorption experiments) are within the experimental RSD displayed in Figure 4 (10-17 \%). This result also indicates that the time of a sorption experiment, including adsorption and desorption phases, can be adjusted to less than 7 hours for this type of material.

\subsection{Limitations of applicability}

While the setup described in this study is suitable for fast measurements of sorption coefficients in laboratory and indoor environments, this setup exhibits some drawbacks. On the first hand, it is important to avoid high leakage between the cell and the material. For homogenous and flat materials, the cell can be directly exposed on the surface. However, porous or rough surfaces cannot be sampled directly and need to be introduced in a sub unit (cylindrical container) made of aluminum, with the FLEC exposed on the top of the container. Even if this method is destructive in the case of porous materials, it still exhibits the 

advantage of reducing the measurement time compared to test chambers. In addition, measurements of sorption coefficients require a fast analytical tool such as the PTR-MS instrument used in this study. In addition, PTR-MS instruments can only measure a limited number of VOCs present in indoor environments and some species such as formaldehyde cannot be measured due to a proton affinity that is only slightly higher than the water proton affinity [34]. Further studies should focus on coupling the FLEC apparatus to other fast analyzers, such as a formaldehyde analyzer to study interactions of this important indoor pollutant with indoor surfaces. Fast analytical tools that are currently under development in several laboratories, designed to measure different compounds, may offer a more compact and lighter alternative than the PTR-MS.

On the other hand, the Langmuir model used to extract sorption parameters neglects the diffusion inside material which is an important key parameter for indoor air quality models. Nevertheless, Jorgensen [40] used previously the Langmuir model and a diffusion model to analyze sorption experiments performed in emission test chambers. They found that the adsorption and desorption coefficients still unchanged between the two models even if the diffusion models determined a supplementary diffusion coefficients. Further works will be conducted to analyze experimental data obtained by the FLEC-PTRMS method, using a model that accounts for the diffusion in the inner of the material, to determine the VOCs diffusion coefficient.

In order to determine the lower values of sorption parameters that could be measured with this method, measurements made on a piece of vinyl flooring exhibiting sorption properties close to that observed for a Pyrex glass, were investigated at different PTR-MS time resolutions. Indeed, an adsorption experiment made at a time resolution of 20 seconds showed that it was not possible to extract sorption coefficients from the desorption phase using equation (5) due to a fast decrease of VOCs concentrations (over a few minutes). Additional experiments were performed at resolution times of 10 and 2 seconds. These experiments showed that $k_{a}$ and $k_{d}$ values could only be extracted from measurements performed at the fastest time resolution of 2 seconds (Table 3 ).

Table 3. Average values of $k_{a} k_{d}$, and $K_{e}$ for a piece of vinyl flooring at a PTR-MS time resolution of 2 seconds. Number of replicates $=5$.

\begin{tabular}{|c|c|c|c|c|c|c|c|c|c|}
\hline \multirow{2}{*}{$\begin{array}{c}\text { VOC } \\
\begin{array}{c}\text { Sorption } \\
\text { parameters }\end{array} \\
\end{array}$} & \multicolumn{3}{|c|}{ Toluene } & \multicolumn{3}{|c|}{ C8 aromatics } & \multicolumn{3}{|c|}{ Benzene } \\
\hline & $\begin{array}{c}\mathbf{k}_{\mathrm{a}} \\
\left(\mathbf{m} \cdot \mathrm{h}^{-1}\right)\end{array}$ & $\begin{array}{c}\begin{array}{c}\mathbf{k}_{\mathrm{d}} \\
\left(\mathbf{h}^{-1}\right)\end{array} \\
\end{array}$ & $\begin{array}{c}\mathbf{K}_{\mathbf{e}} \\
(\mathbf{m})\end{array}$ & $\begin{array}{c}\mathbf{k}_{\mathrm{a}} \\
\left(\mathbf{m} \cdot \mathbf{h}^{-1}\right)\end{array}$ & $\begin{array}{c}\mathbf{k}_{\mathrm{d}} \\
\left(\mathbf{h}^{-1}\right)\end{array}$ & $\begin{array}{c}\mathbf{K}_{\mathbf{e}} \\
(\mathbf{m})\end{array}$ & $\begin{array}{c}\mathbf{k}_{\mathrm{a}} \\
\left(\mathbf{m} \cdot \mathbf{h}^{-1}\right)\end{array}$ & $\begin{array}{c}\mathbf{k}_{\mathbf{d}} \\
\left(\mathbf{h}^{-1}\right)\end{array}$ & $\begin{array}{l}\mathbf{K}_{\mathbf{e}} \\
(\mathbf{m})\end{array}$ \\
\hline Average & 0,06 & 11 & 0,01 & 0,18 & 17 & 0,01 & 0,03 & 8,3 & 0,01 \\
\hline Std & 0,02 & 5,2 & 0,01 & 0,03 & 5,2 & 0,01 & 0,02 & 9,0 & 0,01 \\
\hline RSD (\%) & 28 & 46 & 26 & 18 & 30 & 16 & 57 & 109 & 119 \\
\hline
\end{tabular}

RSD values calculated from 5 replicates range from 15-110\% and are higher than values determined for the gypsum board due to higher noise levels on the PTR-MS measurements at faster time resolutions (Table 3). These results highlight that large uncertainties are associated to the determination of weak sink effects. However, materials exhibiting very weak sink effects will have minor influences on the variation of VOCs concentrations in indoor environments. 
As mentioned above, faster measurements lead to higher noise levels on measured signals, and thus lead to a degradation of the measurement precision. Therefore, the best conditions correspond to a compromise between temporal resolution and noise levels. To determine the best operating conditions of the proposed setup, a set of curves, characteristic of the desorption phase, was simulated at 3 different time resolution (2, 10 and 20 seconds) using equation (4), an air exchange rate of $514 \mathrm{~h}^{-1}$ and several values of adsorption $\left(\mathrm{k}_{\mathrm{a}}\right)$ and desorption $\left(\mathrm{k}_{\mathrm{d}}\right)$ coefficients. To reduce the number of couples for $\mathrm{k}_{\mathrm{a}}$ and $\mathrm{k}_{\mathrm{d}}$, the same value was used for both parameters. The simulations were also performed using experimental values measured for the vinyl flooring at a PTR-MS time resolution of 2 seconds. Equation (4) was fitted on the simulated curves using Sigma Plot to check whether the mathematical fit is capable of retrieving the values of $\mathrm{k}_{\mathrm{a}}$ and $\mathrm{k}_{\mathrm{d}}$ used to generate the curves. The accuracy of the fit was calculated as the difference observed between values of $k_{a}$ and $k_{d}$ used to simulate the curves and values determined by fitting the curve as shown in Table 4.

Table 4. Accuracy determined by simulation for low values of $k_{a}$ and $k_{d}$ for three PTR-MS temporal resolutions.

\begin{tabular}{|c|c|c|c|c|}
\hline Temporal resolution (sec) & $k_{a}\left(m h^{-1}\right)$ & $k_{d}\left(h^{-1}\right)$ & Accuracy $k_{\mathrm{a}}(\%)$ & Accuracy $k_{d}(\%)$ \\
\hline \multirow{6}{*}{2} & 0.01 & 0.01 & 9.89 & 10.00 \\
\hline & 0.02 & 0.02 & 4.71 & 5.00 \\
\hline & 0.10 & 0.10 & 0.10 & 0.10 \\
\hline & 0.01 & 0.10 & 0.001 & 0.60 \\
\hline & 0.10 & 0.01 & 1.20 & 1.00 \\
\hline & 0.03 & 17.00 & 0.33 & 0.24 \\
\hline \multirow{3}{*}{10} & 0.07 & 0.07 & 6.22 & 8.71 \\
\hline & 0.09 & 0.09 & 2.51 & 4.33 \\
\hline & 0.10 & 0.10 & 1.63 & 3.00 \\
\hline \multirow{3}{*}{20} & 0.09 & 0.09 & 5.39 & 10.11 \\
\hline & 0.10 & 0.1 & 3.63 & 7.30 \\
\hline & 0.20 & 0.20 & 0.02 & 0.95 \\
\hline
\end{tabular}

An accuracy lower than $10 \%$ is considered as satisfactory to accurately determine $\mathrm{k}_{\mathrm{a}}$ and $\mathrm{k}_{\mathrm{d}}$. A close inspection of Table 4 indicates that temporal resolutions of 20 and 10 seconds are fast enough to accurately measure adsorption and desorption parameters $\left(\mathrm{k}_{\mathrm{a}} ; \mathrm{k}_{\mathrm{d}}\right)$ as low as $\left(0.09 \mathrm{~m} \cdot \mathrm{h}^{-1} ; 0.09 \mathrm{~h}^{-1}\right)$ and $\left(0.07 \mathrm{~m} \cdot \mathrm{h}^{-1} ; 0.07 \mathrm{~h}^{-1}\right)$, respectively. Faster measurements (2 seconds time resolution) are needed to determine lower values down to $k_{a}=0.01 \mathrm{~m}^{-1} \mathrm{~h}^{-1}$ and $\mathrm{k}_{\mathrm{d}}=0.01 \mathrm{~h}^{-1}$. It is important to note that these results only provide an estimation of the lower values of $k_{a}$ and $\mathrm{k}_{\mathrm{d}}$ that can be measured at a specific time resolution with the FLEC-PTRMS coupling since combinations of different values of $\mathrm{k}_{\mathrm{a}}$ and $\mathrm{k}_{\mathrm{d}}$ are usually observed. Experimental values derived for the vinyl flooring were also tested and they prove that more resolute measurements are necessary to accurately determine sorption coefficients in this range. In addition, these simulations indicated that the determination of low values of $k_{a}$ is more impacted by the temporal resolution than $\mathrm{k}_{\mathrm{d}}$ because the value of $\mathrm{k}_{\mathrm{a}}$ is mainly determined by using the first minutes of the experimental measurements.

\subsection{Literature comparison}

Won [6] measured sorption coefficients for a gypsum board exposed to toluene and ethylbenzene. Tichenor et al. [7] also report sorption coefficients of toluene for the same type 
of material. To the best of our knowledge, there is no measurement of sorption coefficients for benzene available in the literature. Sorption coefficients measured in this study are in the same order of magnitude of previous studies and show a difference by a factor of 2-3 times for $\mathrm{K}_{\mathrm{e}}$ parameter (Table 5). However, a difference is also reported between previous works for the same type of material with ethylbenzene. For the vinyl flooring the difference is more important. This difference can be due to the composition of the tested material as reported by Won [41]. The aging of the surface, or its physicochemical properties may also introduce some variability in the results as observed by Meininghaus [42]. From the other hand, this difference can be due to the inappropriate use of the Tichenor model for emission test chambers used for sorption experiments. The effect of the mass transfer due to the presence of a boundary layer on the surface of the tested material can have an important effect on the determination of sorption parameters. The companion paper (part 2 of this work), will present a comparison using an emission test chamber and the same type of material and the same VOCs mixture. Therefore, different type of models will be used to determine sorption parameters with a consideration for the effect of the mass transfer coefficient and the effect of the boundary layer.

Table 5. Comparison of literature values of $K_{e}$ for a gypsum board with results from this study.

\begin{tabular}{ccccc}
\hline VOCs & $\mathbf{k}_{\mathbf{a}}\left(\mathbf{m} \cdot \mathbf{h}^{-\mathbf{1}}\right)$ & $\mathbf{k}_{\mathbf{d}}\left(\mathbf{h}^{-\mathbf{1}}\right)$ & $\mathbf{K}_{\mathbf{e}}(\mathbf{m})$ & References \\
\hline Benzene & $1.8 \pm 0.57$ & $14 \pm 5.2$ & $0.12 \pm 0.01$ & This work \\
\hline \multirow{2}{*}{ Toluene } & 0.21 & 1.7 & 0.12 & {$[6]$} \\
\cline { 2 - 5 } & $1.6 \pm 0.11$ & $5.4 \pm 0.59$ & $0.29 \pm 0.03$ & This work \\
\hline \multirow{2}{*}{ Ethylbenzene } & 0.21 & 0.87 & 0.24 & {$[6]$} \\
\multirow{2}{*}{ C8 aromatics } & 0.45 & 1.50 & 0.30 & {$[7]$} \\
\cline { 2 - 5 } & $1.3 \pm 0.11$ & $1.8 \pm 0.24$ & $0.72 \pm 0.09$ & This work \\
\hline
\end{tabular}

\section{Conclusions}

The proposed experimental approach, based on a FLEC-PTRMS coupling, has been used successfully to measure sorption coefficients of aromatic compounds on different types of materials. This method presents the advantage to be transportable and non-destructive method for flat and homogeneous material to perform fast measurements in real environments and under indoor conditions. Moreover, this new setup exhibits the advantage of reducing the measurement time to $0.5-8$ hours compared to emission test chambers that require several days of measurements and allows measuring low sorption values. The FLEC/PTR-MS coupling allows measuring low sorption values and will be used for in-situ measurements in energy efficient buildings. Sorption coefficients determined on the field will be then used as inputs for a new indoor air quality model (INCA-indoor) that takes into account the boundary layer effect and the mass transfer coefficient, to predict VOCs concentrations in indoor environments (see companion paper). The FLEC-PTRMS method will be compared in the part 2 of this work, to the traditional emission test chamber method used previously in literature to measure sorption parameters only on the laboratory scale. Further works, will use a more complex model to take into account for the diffusion inside building materials.

\section{Acknowledgments}


The authors would like to thank the French Environment and Energy Management Agency ADEME (Agence De l'Environment et de la Maîtrise de I'Energie) for their financial support in this study, through the MERMAID project (PRIMEQUAL Program).

\section{References}

[1] Jung, C.C., H.J. Su and H.H. Liang, Association between indoor air pollutant exposure and blood pressure and heart rate in subjects according to body mass index. Science of The Total Environment, 2016. 539: p. 271-276.

[2] Vanker, A., W. Barnett, P.M. Nduru, R.P. Gie, P.D. Sly, and H.J. Zar, Home environment and indoor air pollution exposure in an African birth cohort study. Science of The Total Environment, 2015. 536: p. 362-367.

[3] Patelarou, E., N. Tzanakis and F.J. Kelly, Exposure to indoor pollutants and wheeze and asthma development during early childhood. International Journal of Environmental Research and Public Health, 2015. 12(4): p. 3993-4017.

[4] Weschler, C.J., Chemistry in indoor environments: 20 years of research. Indoor Air, 2011. 21(3): p. 205-218.

[5] Singer, B.C., K.L. Revzan, T. Hotchi, A.T. Hodgson and N.J. Brown, Sorption of organic gases in a furnished room. Atmospheric Environment, 2004. 38(16): p. 2483-2494.

[6] Won, D.Y., D.M. Sander, C.Y. Shaw, R.L. Corsi and D.A. Olson, Validation of the surface sink model for sorptive interactions between VOCs and indoor materials. Atmospheric Environment, 2001. 35: p. 4479-4488.

[7] Tichenor, B.A., Z. Guo, J.E. Dunn, L.E. Sparks and M.A. Mason, The Interaction of Vapour Phase Organic Compounds with Indoor Sinks Indoor air 1991. 1(1): p. 23-35.

[8] Little, J.C. and A.T. Hodgson, A strategy for characterizing homogenous, diffusion-controlled indoor sources and sinks. ASTM STP 1287, 1996: p. 293-304.

[9] Deng, B., R. Tian and C. Kim, An analytical solution for VOCs sorption on dry building materials. Heat and Mass Transfer, 2007. 43(4): p. 389-395.

[10] Xu, Y. and Y. Zhang, An improved mass transfer based model for analyzing VOC emissions from building materials. Atmospheric Environment, 2003. 37(18): p. 2497-2505.

[11] Lee, C.S., F. Haghighat and W. Ghaly, A study on VOC source and sink behavior in porous building materials-analytical model development and assessment. Indoor Air, 2005. 15(3): p. 183-196.

[12] Hu, H.P., Y.P. Zhang, X.K. Wang and J.C. Little, An analytical mass transfer model for predicting VOC emissions from multi-layered building materials with convective surfaces on both sides. International Journal of Heat and Mass Transfer, 2007. 50(11-12): p. 2069-2077.

[13] Liu, Z., W. Ye and J.C. Little, Predicting emissions of volatile and semivolatile organic compounds from building materials: A review. Building and Environment, 2013. 64: p. 7-25.

[14] Xiong, J., C. Liu and Y. Zhang, A general analytical model for formaldehyde and VOC emission/sorption in single-layer building materials and its application in determining the characteristic parameters. Atmospheric Environment, 2012. 47: p. 288-294.

[15] M. Rizk, M. Verriele, S. Dusanter, C. Schoemaecker, S. Le Calve, and N. Locoge, Fast sorption measurements of volatile organic compounds on building materials: Part 1 - Methodology developed for field applications. Data in brief, Submitted, 2016.

[16] Carslaw, N., A new detailed chemical model for indoor air pollution. Atmospheric Environment, 2007. 41(6): p. 1164-1179.

[17] Sarwar, G., R. Corsi, Y. Kimura, D. Allen and C.J. Weschler, Hydroxyl radicals in indoor environments. Atmospheric Environment, 2002. 36(24): p. 3973-3988.

[18] An, Y., J.S. Zhang and C.Y. Shaw, Measurements of VOC adsorption/desorption characteristics of typical interior building materials. HVAC\&R Research: International Journal of Heating, Ventilating, Air- Conditioning and Refrigerating Research, 1999. 5(4): p. 297-316. 
[19] Colombo, A., M. De Bortoli, H. Knoppel, E. Pecchio and H. Vissers, Adsorption Of Selected Volatile Organic Compounds On A Carpet, A Wall Coating, And A Gypsum Board In A Test Chamber. INDOOR AIR, 1993. 3(4): p. 276-282.

[20] Popa, J. and F. Haghighat, The impact of VOC mixture, film thickness and substrate on adsorption/desorption characteristics of some building materials. Building and Environment, 2003. 38(7): p. 959-964.

[21] Schripp, T., T. Salthammer, C. Fauck, G. Bekö and C.J. Weschler, Latex paint as a delivery vehicle for diethylphthalate and di-n-butylphthalate: Predictable boundary layer concentrations and emission rates. Science of The Total Environment, 2014. 494-495: p. 299305.

[22] Bouhamra, W. and A. Elkilani, Development of a Model for the Estimation of Indoor Volatile Organic Compounds Concentration Based on Experimental Sorption Parameters. Environmental Science \& Technology, 1999. 33(12): p. 2100-2105.

[23] Kirchner, S., F. Maupetit, D. Quenard, P. Rouxel and D. Giraud, Characterization of adsorption/desorption of volatile organic compounds on indoor surface materials. Healthy Buildings 95, proceedings of a conference held Milan, 1995: p. 953-958.

[24] Jorgensen, R.B. and O. Bjorseth, Sorption behaviour of volatile organic compounds on material surfaces - The influence of combinations of compounds and materials compared to sorption of single compounds on single materials. Environment International, 1999. 25(1): p. 17-27.

[25] Wouda, P., P.M. Bluyssen, H.J.M. Cornelissen, A.W. Hoogeveen and J.F.V.d. Wal, Chemical and sensory evaluation of sorption effects of chemicals on combined indoor materials in comparison to sorption effects on the individual materials. Proceedings of Healthy Buildings '97, Washington DC, 1997. 2: p. 225-230.

[26] Schoemaecker, C., M. Verriele, B. Hanoune, D. Petitprez, N. Leclerc, M. Rizk, S. Dusanter, S. Le Calve, M. Millet, P. Bernhardt, M. Mendez, N. Blond, D. Hauglustaine, A. Clappier, P. Blondeau, M. Abadie, and N. Locoge, Experimental and modeling characterizations of indoor air quality in low energy public buildings in france - The mermaid program. Proceedings to Indoor Air 2014: p. 573-580.

[27] Mendez, M., N. Blond, P. Blondeau, C. Schoemaecker and D.A. Hauglustaine, Assessment of the impact of oxidation processes on indoor air pollution using the new time-resolved INCAIndoor model. Atmospheric Environment, 2015. 122: p. 521-530.

[28] Pekey, H. and D. Arslanbaş, The Relationship Between Indoor, Outdoor and Personal VOC Concentrations in Homes, Offices and Schools in the Metropolitan Region of Kocaeli, Turkey. Water, Air, and Soil Pollution, 2008. 191(1-4): p. 113-129.

[29] Sarigiannis, D.A., S.P. Karakitsios, A. Gotti, I.L. Liakos and A. Katsoyiannis, Exposure to major volatile organic compounds and carbonyls in European indoor environments and associated health risk. Environment International, 2011. 37(4): p. 743-765.

[30] Sofuoglu, S.C., G. Aslan, F. Inal and A. Sofuoglu, An assessment of indoor air concentrations and health risks of volatile organic compounds in three primary schools. International Journal of Hygiene and Environmental Health, 2011. 214(1): p. 36-46.

[31] Blake, R.S., P.S. Monks and A.M. Ellis, Proton-Transfer Reaction Mass Spectrometry. Chemical Reviews, 2009. 109(3): p. 861-896.

[32] Schripp, T., S. Etienne, C. Fauck, F. Fuhrmann, L. Märk, and T. Salthammer, Application of proton-transfer-reaction-mass-spectrometry for Indoor Air Quality research. Indoor Air, 2014. 24(2): p. 178-189.

[33] Wolkoff, P., An emission cell for measurement of volatile organic compounds emitted from building materials for indoor use - the field and laboratory emission cell FLEC. GefahrstoffeReinhaltung der Luft, ALLEMAGNE, 1996a. 56: p. 151-157.

[34] De Gouw, J. and C. Warneke, Measurements of volatile organic compounds in the earth's atmosphere using proton-transfer-reaction mass spectrometry. Mass Spectrom Rev, 2007. 26(2): p. 223-57. 
[35] Zhang, L.Z. and J.L. Niu, Laminar fluid flow and mass transfer in a standard field and laboratory emission cell. International Journal of Heat and Mass Transfer, 2003. 46(1): p. 91100.

[36] M. Rizk, M. Verriele, M. Mendez, N. Blond, S. Dusanter, C. Schoemaecker, P. Blondeau, S. Le Calve, and N. Locoge, Fast sorption measurements of volatile organic compounds on building materials: Part 2 - Comparison between FLEC and CLIMPAQ Methods Data in brief, Submitted, 2016.

[37] Zhu, Q., S. Kato, S. Murakami and K. Ito, 3D-CFD analysis of diffusion and emission of VOCs in a FLEC cavity. Indoor Air, 2007. 17(3): p. 178-188.

[38] Liu, X., Z. Guo, L.E. Sparks and N.F. Roache, VOC sink behaviour on building materials-model evaluation. Indoor and Built Environment, 2012. 20(6): p. 661-676.

[39] Meininghaus, R., L. Gunnarsen and H.N. Knudsen, Diffusion and Sorption of Volatile Organic Compounds in Building Materialsâ^'Impact on Indoor Air Quality. Environmental Science \& Technology, 2000. 34(15): p. 3101-3108.

[40] Jorgensen, R.B., T.H. Dokka and O. Bjorseth, Introduction of a Sink-Diffusion Model to Describe the Interaction between Volatile Organic Compounds (VOCs) and Material Surfaces, 2000, Munksgaard International Publishers. p. 27-38.

[41] Won, D., R.L. Corsi and M. Rynes, New Indoor Carpet as an Adsorptive Reservoir for Volatile Organic Compounds. Environmental Science \& Technology, 2000. 34(19): p. 4193-4198.

[42] Meininghaus, R. and E. Uhde, Diffusion studies of VOC mixtures in a building material. Indoor Air, 2002. 12(4): p. 215-222. 


\section{Highlights}

- Development of a new methodology to measure in-situ VOCs sorption on building materials

- Evaluation of sorption parameters under real conditions within few hours

- Measurement of low sorption properties with $10 \%$ of accuracy

- Sorption parameters are useful to IAQ models to predict VOCs concentration indoors 